\title{
Measuring Aerosol Phase Changes and Hygroscopicity with a Microresonator Mass Sensor
}

\author{
Arthur T. Zielinski ${ }^{1, * \dagger}$, Peter J. Gallimore ${ }^{1, * \dagger}$, Paul T. Griffiths ${ }^{1,2}$, Roderic L. Jones ${ }^{1}$, Ashwin A. Seshia ${ }^{3}$, \\ and Markus Kalberer ${ }^{1}$ \\ ${ }^{1}$ Centre for Atmospheric Science, Department of Chemistry, University of Cambridge, Cambridge CB2 1EW, U.K. \\ ${ }^{2}$ National Centre for Atmospheric Science, NCAS, Cambridge CB2 1EW, U.K. \\ ${ }^{3}$ The Nanoscience Centre, Department of Engineering, University of Cambridge, Cambridge CB3 OFF, U.K.
}

\begin{abstract}
The interaction between atmospheric aerosol particles and water vapor influences aerosol size, phase and composition, parameters which critically influence their impacts in the atmosphere. Methods to accurately measure aerosol water uptake for a wide range of particle types are therefore merited. We present here a new method for characterizing aerosol hygroscopicity, an impaction stage containing a MicroElectroMechanical Systems (MEMS) microresonator. We find that deliquescence and efflorescence relative humidities (RHs) of sodium chloride and ammonium sulfate are easily diagnosed via changes in resonant frequency and peak sharpness. These agree well with literature values and thermodynamic models. Furthermore, we demonstrate that unlike other resonatorbased techniques, full hygroscopic growth curves can be derived, including for an inorganic-organic mixture (sodium chloride and malonic acid) which remains liquid at all RH. The response of the microresonator frequency to temperature and particle mechanical properties, and the resulting limitations when measuring hygroscopicity, are discussed. MEMS resonators show great potential as miniaturized ambient aerosol mass monitors and future work will consider the applicability of our approach to complex ambient samples. The technique also offers an alternative to established methods for accurate thermodynamic measurements in the laboratory.
\end{abstract}

Aerosols are an important component of the atmosphere with respect to climate ${ }^{1}$ and human health ${ }^{2}$. Interaction between aerosol particles and water vapor in the atmosphere can result in changes of critical aerosol properties including size, phase and composition. Particle water content has been shown to be an important parameter for visibility in urban areas ${ }^{3}$, heterogeneous uptake and hydrolysis of atmospheric trace gases ${ }^{4}$, and inparticle diffusivity ${ }^{5}$, with concurrent impacts on chemical aging and gas-particle exchange. When considering the health impacts of airborne particles, deposition in the lungs is strongly dependent on particle size ${ }^{6}$.

Hygroscopic aerosols show a propensity to absorb water vapor as the ambient relative humidity $(\mathrm{RH})$ increases. For some systems, including many inorganic salts, initially solid particles undergo a phase transition to aqueous droplets at a well-defined deliquescence RH (DRH). Further increases in RH result in growth of the aqueous droplet by additional water uptake. Aerosol deliquescence and growth are equilibrium properties of particles dependent on the ambient temperature and relative humidity (or more precisely, water activity). When the ambient $\mathrm{RH}$ is now decreased, the aerosol water content also decreases, until in some cases the aerosol effloresces, reverting to a solid. The efflorescence RH (ERH) is typically lower than the thermodynamic DRH due to kinetic limitations on crystallization in small droplets. Consequently, efflorescence of a given substance is observed over a range of relative humidity. In practice, many aerosols including some single-component organic particles and most particles containing complex mixtures of compounds do not effloresce, meaning that distinct efflorescence and deliquescence behavior is not observed, even if it is thermodynamically predicted. ${ }^{7,8}$

A common approach to quantifying hygroscopic growth is in terms of an aerosol mass growth factor (GF), $m / m_{0}$, where the aerosol mass at a given $\mathrm{RH}(\mathrm{m})$ is normalized to the dry mass $\left(m_{0}\right)$. A number of analytical methods exist to assess aerosol water uptake. One of the most prominent is the electrodynamic balance (EDB), where a single micron-sized particle is levitated in an electrostatic trap while the surrounding gas phase (including $\mathrm{RH}$ ) can be modified. EDBs permit precise determination of DRH and GFs and have been used to assess a number of standard single component aerosols and mixtures ${ }^{9-11}$, large particles such as pollen ${ }^{12}$, and organic compounds subject to chemical aging ${ }^{13}$. Yet, interrogating ambient particles, or any submicron particles (the dominant mode in the atmosphere), must be indirectly achieved by sample collection and re-suspension ${ }^{14}$. Other single particle approaches including optical tweezers have also been used to study particle water uptake ${ }^{15,16}$.

Alternatively, Hygroscopicity Tandem Differential Mobility Analyzers (HTDMAs) dry and size-select particles from an ensemble, and determine size changes resulting from water uptake at higher RH. HTDMAs enable particles in the submicron range, including ambient particles, to be assessed, and have been used with success in a number of laboratory and field studies ${ }^{17-20}$. The instruments require a continuous flow of particles, so the time required to record a humidogram (1 hour or more ${ }^{21}$ ) may be a limitation for rapidly changing aerosol populations. In addition, monitoring other particle characteristics (e.g. composition) requires separate instrumentation, and size and cost may be prohibitive for some applications. 
Other approaches to detecting the DRH and ERH include using an interdigitated electrode (IDE) sensor or a quartz crystal microbalance (QCM). The IDE sensor detects phase changes through a change in measured impedance and can reliably determine DRH and ERH. ${ }^{22}$ A QCM acts as a mass sensor with the resonant frequency being related to the total mass of the crystal (plus any collected particles or films). Traditionally, as particles are added to the surface the additional mass is registered as a negative frequency shift. When applied to deliquescing particles, however, Arenas et al. showed that the resonant frequency increased implying the change in damping due to the phase change (higher damping for liquid phase) dominated over the change in mass. ${ }^{23}$ This is a similar response to the coupled model introduced by Dybwad which highlights the influence of particle attachment stiffness on the resonator response. ${ }^{24}$ In particular, large particles loosely bound to the sensor surface $(e . g$. $>5 \mu \mathrm{m}$ for a $6 \mathrm{MHz} \mathrm{QCM}^{25}$ ) can cause elastic loading (rather than inertial loading) to produce a positive frequency shift. ${ }^{26}$ Arenas et al. were still able to use their measured frequency shifts to determine the DRH for a range of salts including mixtures of organic and inorganic salts. Both of these approaches offer a smaller testing platform with small internal volumes. This has the major advantage of shorter RH equilibrium times meaning the total experimental time is greatly reduced and deployment in the field is potentially more straightforward and cost effective. The major limitation is that, up to now, they have only been used to measure the humidities at deliquescence/efflorescence and full growth curves have not been demonstrated.

An alternative approach presented here applies a MicroElectroMechanical Systems (MEMS) microresonator which operate in a similar fashion to the QCM. MEMS resonators typically offer higher sensitivities than QCM resonators (depending on operating mode ${ }^{27}$ ) with the additional benefit of simple integration into electronic systems since they are fabricated using the same batch processes. ${ }^{28}$

This work introduces, to the authors' knowledge, the first application of MEMS microresonators for the measurement of aerosol hygroscopic growth. Microresonators have previously been used to measure changes in ambient relative humidity ${ }^{29}$, typically by adding hygroscopic coating to their surface ${ }^{30,31}$. A growing field also exists for measuring particulate matter with MEMS microresonators. ${ }^{32-35}$ Their small size and weight, and ability to monitor submicron particle mass make microresonators attractive for ambient monitoring. Here we demonstrate that water uptake by hygroscopic inorganic and organic aerosols can be quantified. Particles are collected via impaction using the MEMS Impactor Stage (MIS) ${ }^{35}$ with particle mass and phase monitored in response to ambient RH changes. The approach allows for the measurement of multiple particles simultaneously (including mixtures and ambient particles) unlike an EDB while also measuring the same particles throughout the experiment unlike an HTDMA.

The MIS system was shown to be highly effective in determining the DRH and ERH of inorganic salts. Hygroscopic growth curves were extracted from the data and agreed well with previous literature. An inorganic-organic mixture showing continuous water uptake was tested as a closer proxy for ambient aerosols which also agreed well with thermodynamic predictions. MEMS microresonators are a promising method for determining aerosol hygroscopicity, particularly for ambient applications where compact, submicron particulate mass measurements are clearly warranted.

\section{EXPERIMENTAL SECTION}

Resonator mass sensors. The hygroscopic growth of sodium chloride $(\mathrm{NaCl})$, ammonium sulfate (AS), and a mixture of sodium chloride and malonic acid $(\mathrm{NaCl} / \mathrm{MA})$ were measured using piezoelectric bulk acoustic wave resonators. The resonators, shown in Figure 1, are suspended $1.4 \mathrm{~mm} \times 1.4 \mathrm{~mm}$ square plates with a maximum thickness of $11.7 \mu \mathrm{m}$ fabricated from silicon-on-insulator wafers using a commercial foundry process. The fabrication process follows the description by Prasad et al..$^{36}$ The resulting resonator is composed primarily of silicon $(10 \mu \mathrm{m} \pm 1 \mu \mathrm{m})$ with thin layers of silicon oxide $(0.2 \mu \mathrm{m})$, piezoelectric aluminum nitride $(0.5 \mu \mathrm{m})$, and chromium/aluminum metal electrodes $(1 \mu \mathrm{m})$. Two triangular electrodes on the top surface of the resonator are used for transduction in a two-port configuration meaning one electrode is used for actuating the resonator and the second electrode for sensing the resonator response. Together with grounding the resonator body, this transduction configuration limits the effect of parallel feedthrough capacitance which can otherwise limit signal magnitude and accuracy. The grounding of the resonator body also reduces the likelihood of particle charge (e.g. from the size selection procedure, see below) affecting the resonator response.

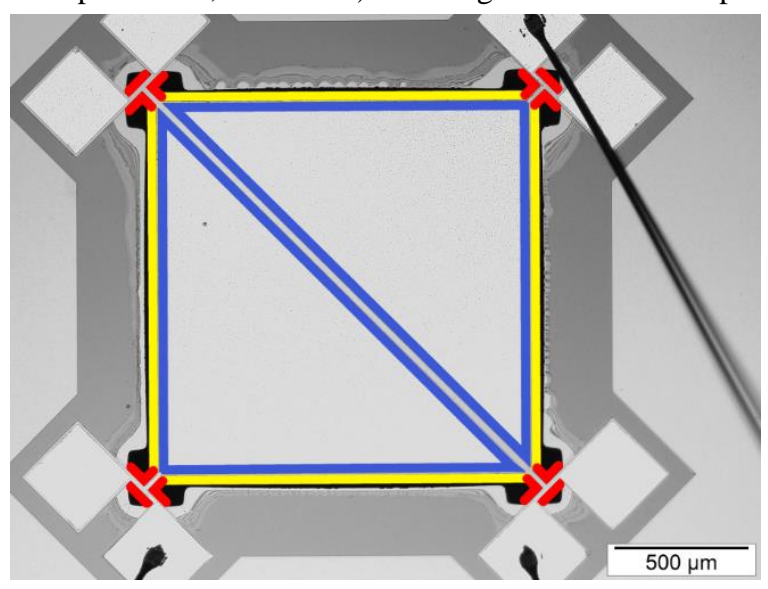

Figure 1. Image of front resonator surface with two triangular, piezoelectric electrodes. The resonator is suspended by T-shaped anchors at each of the four corners. Resonator components highlighted with colored borders: resonator body (yellow), electrodes (blue), and anchors (red). Image taken with an optical microscope (BX51, Olympus).

The response of the resonator (measured as the output-to-input ratio) reaches a maximum when the driving oscillating signal, provided by a network analyzer (N9915A, Agilent), oscillates at the resonant frequency of a vibrational mode of the resonator. For this work, the in-plane square-extensional (SE) mode was chosen given its relatively high mass sensitivity and applicability to a range of resonator topologies. The SE mode is characterized by symmetric extension/contraction along orthogonal axes producing a node at the resonator center and antinodes at the corners (for a square resonator). The SE mode for the resonators here occurred at $\sim 3.12 \mathrm{MHz}$ without any collected particles.

When particles are added onto the resonator surface (collected on the back of the resonator to protect electrical contacts) the resonant frequency is reduced (i.e. the vibration slows due to the added mass) in a relationship that is considered linear with mass for small mass additions. The linear assumption is 
better suited for uniform thin-film mass addition since particle mass addition includes confounding factors such as spatial sensitivity $^{37,38}$, particle stacking ${ }^{37,39}$, and attachment stiffnesses ${ }^{24}$. Regardless, most microresonator particulate mass sensors continue to make the assumption of a linear frequency response to mass $^{32,33,35,40}$. For the current application the specific conversion factor between the added particle mass and the resulting frequency change is not required since hygroscopic growth is presented as a ratio of wet-to-dry mass.

Particle preparation and collection. Aerosol particles were prepared from solution using a custom-built nebulizer. Sodium chloride $(\mathrm{NaCl}, 99 \%)$, ammonium sulfate $\left(\left(\mathrm{NH}_{4}\right)_{2} \mathrm{SO}_{4}\right.$, AS, $99.5 \%)$ and malonic acid $\left(\mathrm{CH}_{2}(\mathrm{COOH})_{2}\right.$, MA, $\left.99 \%\right)$ were obtained from Sigma-Aldrich and dissolved in water (HPLC grade, VWR). The following aqueous solutions were prepared at a total solute concentration of $2 \mathrm{~g} / \mathrm{L}$ : $\mathrm{NaCl}, \mathrm{AS}$, and $\mathrm{NaCl} / \mathrm{MA}$ in a 1:1 molar ratio. The nebulizer was supplied with nitrogen gas (oxygen-free, BOC) using a mass flow controller (179C, MKS) with an output flow rate of $2 \mathrm{~L} / \mathrm{min}$. The particle stream was then dried to $\mathrm{RH}<5 \%$ using a silica diffusion drier with excess flow vented.

The general flow schematic for particle collection is shown in Figure 2. The polydisperse particle flow was electrostatically size-selected to $300 \mathrm{~nm}$ using a differential mobility analyzer (DMA, Model 3081, TSI Inc.). Size selection allows the collected mass delivered to the resonator to be estimated using a condensation particle counter (CPC, Model 3776, TSI Inc.) and removes the size dependence of attachment stiffness ${ }^{24}$.

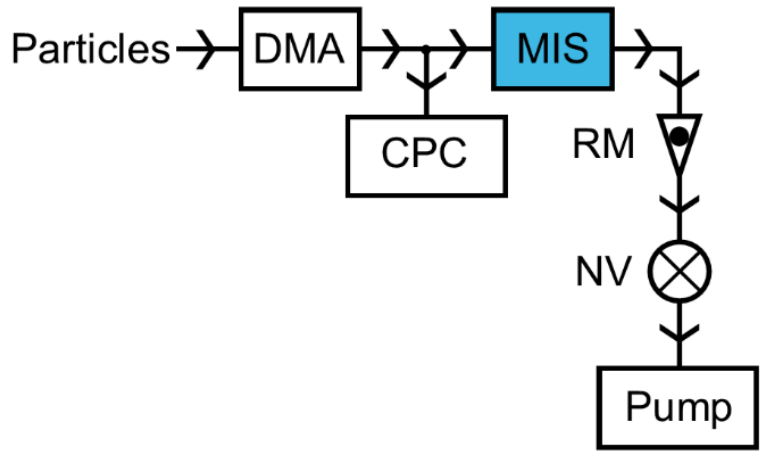

Figure 2. Flow schematic of particle collection onto a microresonator housed in the MEMS Impactor Stage (MIS) with black arrows designating flow direction. During collection, particles are size-selected by a differential mobility analyzer (DMA) before reaching the MIS which collects particles onto a microresonator via inertial impaction. The upstream particle concentration is recorded by a condensation particle counter (CPC). Flow is pulled through the system by a vacuum pump and controlled using a needle valve (NV) and rotameter $(\mathrm{RM})$.

The size-selected particles were subsequently collected onto the microresonators using the MEMS Impactor Stage (MIS) which is explained in detail elsewhere ${ }^{35}$. The MIS is a singlestage impactor designed to collect particles on a variety of microresonator topologies. The nozzle of the MIS is interchangeable to vary the impaction cut-off diameter (the diameter at which $50 \%$ of particles are collected). For this study, particles were collected using a nozzle with $3 \times 0.25 \mathrm{~mm}$ diameter circular jets with a cut-off diameter on the order of $200 \mathrm{~nm}$ for a flow rate of $0.7 \mathrm{LPM}$. The MIS includes electrical ports for resonator transduction as well as a combined temperature and RH sensor (SHT21, Sensirion). The RH calibration was confirmed to be within the rated $\pm 2 \%$ by comparing to saturated salt solutions of sodium chloride and potassium chloride.

Each salt was collected for one hour; the same resonator was used for both $\mathrm{NaCl}$ and $\mathrm{NaCl} / \mathrm{MA}$, with a different resonator of the same design used for $\mathrm{AS}$. Between $\mathrm{NaCl}$ and $\mathrm{NaCl} / \mathrm{MA}$ collection the resonator was cleaned with methanol and water using a solvent rinsing technique described elsewhere ${ }^{41}$. Following cleaning, the resonant frequency was recovered to within $20 \mathrm{~Hz}(<1 \mathrm{ng}$ ) of the original clean frequency (Table S-1). Images of the resonator collection surface (Figure S-1) before $\mathrm{NaCl}$ collection and before $\mathrm{NaCl} / \mathrm{MA}$ (i.e. after cleaning) are qualitatively similar and contrast with particle-laden surfaces as shown in Zielinski et al. ${ }^{41}$. The cleaning approach is safe and minimally invasive compared to current alternatives including ultrasonication, $\mathrm{CO}_{2}$ snow jets, and the use of sacrificial coating layers ${ }^{42}$. These alternatives also require large lab equipment (e.g. an ultrasonic bath) and/or high temperatures $\left(>100^{\circ} \mathrm{C}\right)$ to reapply photoresists. Recently, a non-invasive approach has been partially successful for large particle aggregates using polarized resonators ${ }^{43}$ but a reliable means of in-situ cleaning for sub-micron particles would be desirable in the future.

The resonator response was recorded for each collection at one-minute intervals to ensure a consistent total frequency shift for each particle type (on the order of $1100 \mathrm{~Hz}$ equivalent to an estimated mass loading of $0.04 \mu \mathrm{g}$ using a theoretical sensitivity of $0.034 \mathrm{ng} / \mathrm{Hz}^{35}$ ). The resonant frequency measurements also provide the unloaded resonant frequency for later hygroscopicity measurements.

Response to relative humidity. The collected particles were exposed to changing relative humidity by flowing a mixture of humidified and dry nitrogen gas over the resonator (still housed within the MIS) at a total flow rate of 2 LPM. The humidified flow was produced by passing dry nitrogen through a bubbler containing HPLC-grade water. The RH of the total flow was then controlled by varying the relative flows of the humidified and dry gas streams as controlled by two mass flow controllers (179C, MKS). To avoid the pressure drop across the impactor nozzle (which would otherwise lower the internal RH readings $\left.{ }^{44}\right)$, the $3 \times 0.25 \mathrm{~mm}$ nozzle was replaced by a $1 \times 1.70 \mathrm{~mm}$ nozzle with negligible pressure drop.

Prior to determining hygroscopic growth curves, each collection of particles was deliquesced $(>85 \% \mathrm{RH})$ and effloresced $(<5 \% \mathrm{RH})$. This allowed for any redistribution of mass on the resonator surface which could otherwise result in mass-independent frequency changes during humidogram acquisition.

Humidograms were acquired by ramping the $\mathrm{RH}$ in consecutive steps from $\sim 0 \%$ to $\sim 90 \%$ (which we refer to as the "humidification mode") and then returning to $\sim 0 \%$ ("drying mode"). Five frequency scans were recorded (on a roughly 25 second interval) at each RH step. After changing the RH (i.e. changing the relative flow rates), the system was left to equilibrate for 5 minutes for lower RH $(<75 \%)$ and up to 15 minutes at higher $\mathrm{RH}(>75 \%)$. The procedure was repeated for the $\mathrm{NaCl}$ collection to highlight the repeatability of the resonator response, but otherwise done once for $\mathrm{AS}$ and the $\mathrm{NaCl} / \mathrm{MA}$ mixture.

The frequency response was recorded based on an input power of -10 or $0 \mathrm{dBm}$ (avoiding non-linear frequency responses $^{45}$ ) across a span of $16-20 \mathrm{kHz}$ with 801 points (for a discrete resolution of $\pm 20-25 \mathrm{~Hz}$ corresponding to a theoretical 
mass resolution of $680-850 \mathrm{pg}$ ). The resonant frequency and quality factor were extracted from the frequency response based on fitting a Lorentzian function ${ }^{46}$, neglecting minor influences of capacitive feedthrough ${ }^{47}$.

Modelling methods. Our results are compared with thermodynamic calculations performed using the Extended Aerosol Inorganics Model (E-AIM, http://www.aim.env.uea.ac.uk/aim/aim.php). The water content of $\mathrm{NaCl}, \mathrm{AS}$ and $\mathrm{NaCl} / \mathrm{MA}(1: 1$ molar ratio) aerosols was calculated as a function of ambient relative humidity $(\mathrm{RH})$ at 298.15 K. E-AIM model III was employed and the water activity of MA was calculated using the fitted activity model of Clegg and Seinfeld ${ }^{48}$. Two humidification mode curves were calculated for the $\mathrm{NaCl} / \mathrm{MA}$ mixture: One assuming initially solid particles where both the $\mathrm{NaCl}$ and $\mathrm{MA}$ phases deliquesce, and a second where solid MA formation was suppressed, prompted by previous studies which report that MA aerosol remains liquid at all $\mathrm{RH}^{9,10,48}$. Drying mode curves were calculated by suppressing all solid formation. Aerosol thermodynamic properties are only weakly temperature dependent and we expect the temperature difference between the model (298.15 K) and the measurements (292-295 K with each individual experiment $\pm 1 \mathrm{~K})$ to be negligible $(<1 \%)$ when comparing modelled and measured DRH and $m / m_{0}{ }^{49}$.

\section{RESULTS AND DISCUSSION}

Inorganic salts (NaCl, AS). Typical raw data obtained from an experiment to assess aerosol phase changes and hygroscopicity using MEMS are shown for $\mathrm{NaCl}$ in Figure 3. Fig 3a shows the measured resonator signal magnitude as a function of frequency, for particles exposed to dry ambient conditions $(0 \%$ RH) and humid ambient conditions (89\% RH). We monitor changes in two peak parameters during an experiment, namely the resonant frequency $(f)$, and the quality factor (Q-factor). The resonant frequency corresponds to the driving frequency with the maximum response. The Q-factor is a measure of peak "sharpness" and is related to the extent of damping of the resonator. It is calculated based on the ratio of the resonant frequency to the half-power bandwidth (corresponding to a $3 \mathrm{~dB}$ response reduction). As shown in Fig 3a, both change in response to ambient RH. This is related to water uptake by particles on the resonator surface; the bare resonator does not show an $\mathrm{RH}$ response. The shift down in frequency is related to the mass increase following water uptake while the reduction in amplitude and widening of the peak (reduced Q-factor) correspond to increased damping by the deliquesced particles.

To interpret these peak changes quantitatively, we assume an inverse linear relationship between frequency and particle mass for small mass additions ${ }^{32,37,50,51}$ - water uptake or other particle mass increase decreases the measured frequency. The Q-factor is a function of the material properties, particularly phase, of particles on the resonator surface. The resonator frequency and Q-factor can therefore provide diagnostic information about particle phase changes as a function of $\mathrm{RH}$, which for $\mathrm{NaCl}$ are very well understood.

In the "humidification mode" data in Figure $3 b$ (increasing RH from dry), a clear discontinuity in both the frequency and Q-factor is present between 72 and $77 \% \mathrm{RH}$, corresponding to the $\mathrm{DRH}$ of $\mathrm{NaCl}$ where a solid to aqueous phase transition occurs. A similar discontinuity can be seen in the "drying mode" data (decreasing RH from humid) between 40 and $50 \% \mathrm{RH}$, corresponding to particle efflorescence.

A number of features of the MEMS resonator useful for diagnosing phase changes are apparent from Figure 3. Firstly, clear step-changes in the frequency and Q-factor are observed following phase transitions. Secondly, the DRH and ERH determined here agree well with previous literature determinations from experiments and thermodynamic modelling (Table 1). The range in DRH (4-5\%) and ERH (5-9\%) reported here is related to the $\mathrm{RH}$ step size in our experiments and could be reduced for a more precise determination. Thirdly, the frequency response of the resonator also allows the hygroscopicity of the particles to be assessed. Above the DRH, for example, the frequency continues to decrease in response to additional hygroscopic growth of $\mathrm{NaCl}$. Changes in the Q-factor cannot be quantitatively related to hygroscopic growth and so we only use the Q-factor as a sensitive probe of phase changes.

Table 1. Comparison of deliquescence and efflorescence RHs determined in this study with previous experimental determinations. Two repeats were performed for $\mathrm{NaCl}, \mathrm{a}=\mathrm{Run} \mathbf{1}, \mathrm{b}=\mathrm{Run} 2$, which show good agreement. Literature references include a range of methods including EDB $^{10,52}$, HTDMA $^{53}$, Fourier Transform Infrared Spectroscopy (FT-IR) ${ }^{54,55}$, QCM ${ }^{23}$, and IDE $^{22}$. Experimental values given for temperatures ranging from 294-299 K. Predicted DRHs from E-AIM are included.

\begin{tabular}{l|ccc|cc}
\hline \multirow{2}{*}{ Salt } & \multicolumn{3}{|c|}{ Deliquescence RH $(\%)$} & \multicolumn{2}{c}{ Efflorescence RH (\%) } \\
\cline { 2 - 6 } & This work $( \pm 2 \%)$ & E-AIM & Literature & This work $( \pm 2 \%)$ & Literature \\
\hline \multirow{2}{*}{$\mathrm{NaCl}$} & $\begin{array}{l}72-77^{\mathrm{a}}, \\
71-75^{\mathrm{b}}\end{array}$ & 75 & $75.5^{10}, 77 \pm 2^{23}, 75 \pm 1^{54}, 75 \pm 1^{53}, 76^{22}$ & $\begin{array}{l}42-51^{\mathrm{a}} \\
46-51^{\mathrm{b}}\end{array}$ & $50^{55}, 50^{22}$ \\
\hline$\left(\mathrm{NH}_{4}\right)_{2} \mathrm{SO}_{4}$ & $79-81$ & 80 & $80^{52}, 83 \pm 3^{23}, 81 \pm 2^{54}, 79 \pm 1^{53}$ & $35-43$ & $37^{52}$ \\
\hline
\end{tabular}




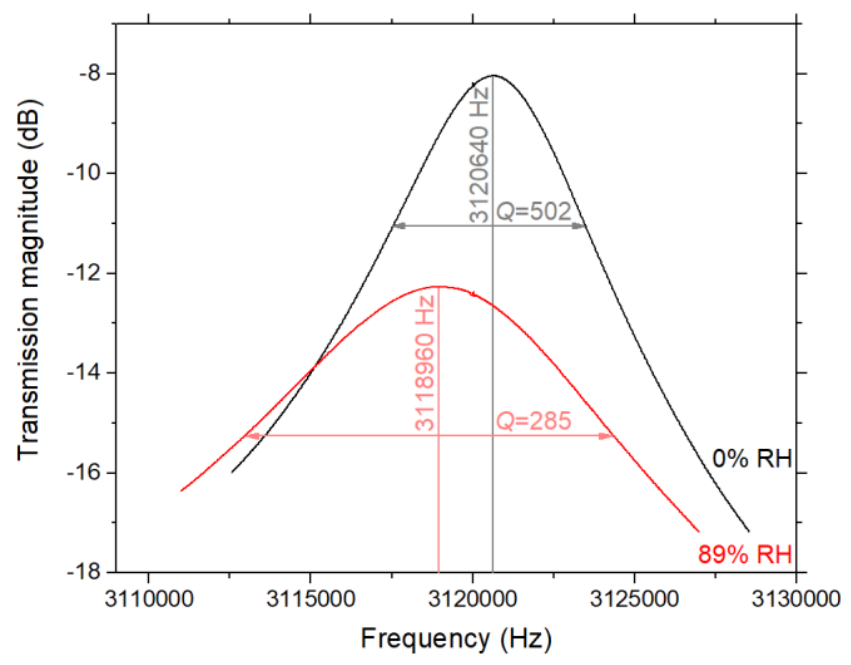

(a)

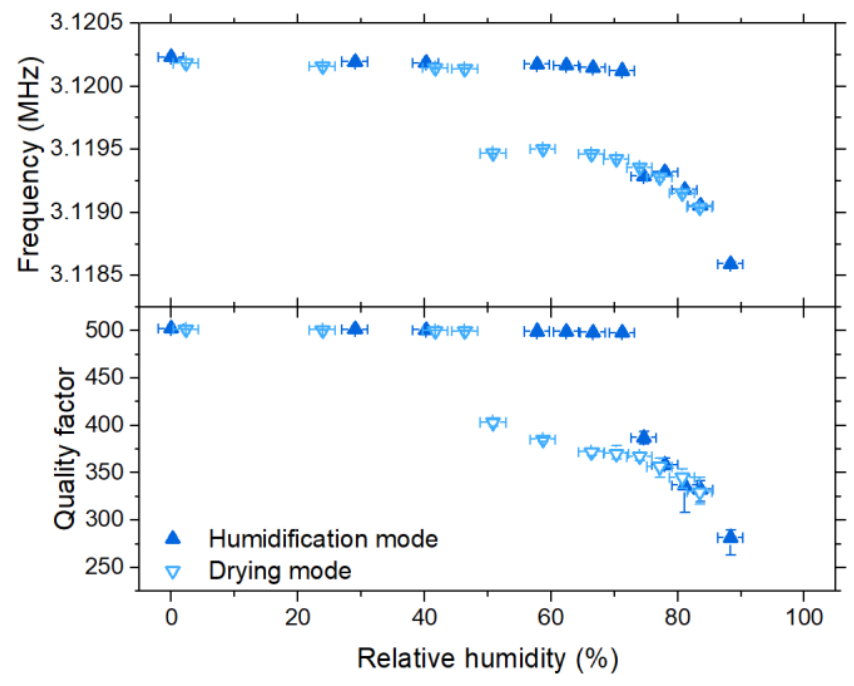

(b)

Figure 3. Raw data for the second RH cycle of the collected $\mathrm{NaCl}$ particles. Panel (a) shows the resonator response (transmission magnitude) across a sweep of frequencies for dry (black) and humid (red) conditions during the humidification mode. The changes in resonant frequency and quality factor are highlighted by vertical lines and horizontal arrows, respectively. Panel (b) shows the resonant frequencies (corrected for temperature) and quality factors at each $\mathrm{RH}$ across both the humidification mode (dark, filled upwards triangles) and the drying mode (light, open downwards triangles). Vertical error bars show the range of the five measurements with the quoted value being the average. Horizontal error bars are based on RH uncertainty $( \pm 2 \%)$.

We quantify the aerosol hygroscopic growth by converting the measured raw frequencies into mass growth factors, $\mathrm{m} / \mathrm{m}_{0}$. We first correct the raw frequencies for temperature variations during an experiment ( $1 \mathrm{~K})$. Frequency scales linearly with temperature for the unloaded resonator surface ${ }^{36}$ and so a scaling factor of $-102 \mathrm{~Hz} \mathrm{~K}^{-1}$ was applied to correct the frequency to a "reference" temperature at the start of the experiment. At this stage, the frequency change during an experiment scales well with the theoretical growth curve of $\mathrm{NaCl}$ (Figure 4).
We next calculate the frequency change corresponding to the added mass at a given $\mathrm{RH}$ (including water uptake) relative to the bare resonator, and then normalize this to the frequency change for dry particles assessed during resonator loading. To obtain a quantitative agreement between this frequency ratio and the predicted $\mathrm{m} / \mathrm{m}_{0}$, we find that an additional correction is required. Specifically, we add a single additional frequency shift to all data obtained for liquid particles, relative to the solid reference state. Our hypothesis is that this correction is required to account for the (typically neglected) change in attachment stiffness of particles to the resonator surface following a phase transition. The theoretical basis for this phenomenon, the derivation of the correction factor, and the shifts applied to each sample type are described in the supporting information including the corresponding scaling of $\mathrm{m} / \mathrm{m}_{0}$ (Table S-2).

Figure 5 shows the final growth curves obtained for $\mathrm{NaCl}$ using the MEMS resonator, and the results from E-AIM for comparison. The two "runs" correspond to repeats of the humidity variation procedure for the same salt collection and agree well with each other over the entire RH range measured. Run 1 and Run 2 were corrected independently for changes in particle attachment stiffness and the extracted "stiffness frequencies" agree to within $5 \%$.

The measured humidification mode curves also show excellent agreement with the E-AIM prediction in terms of the DRH and mass growth factor at higher RH. The drying mode data follow the expected decrease in $\mathrm{m} / \mathrm{m}_{0}$ until $\sim 65 \% \mathrm{RH}$, at which point a "levelling off" occurs until the ERH (40-50\%) in contrast to the expected decrease (dashed line in Figure 5). This corresponds to conditions where the $\mathrm{NaCl}$ solute is supersaturated and crystallization is kinetically limited. We suspect the discrepancy in this RH range is an artefact related to the contact between deposited material and the MEMS surface, and consider possible explanations in the discussion section below.

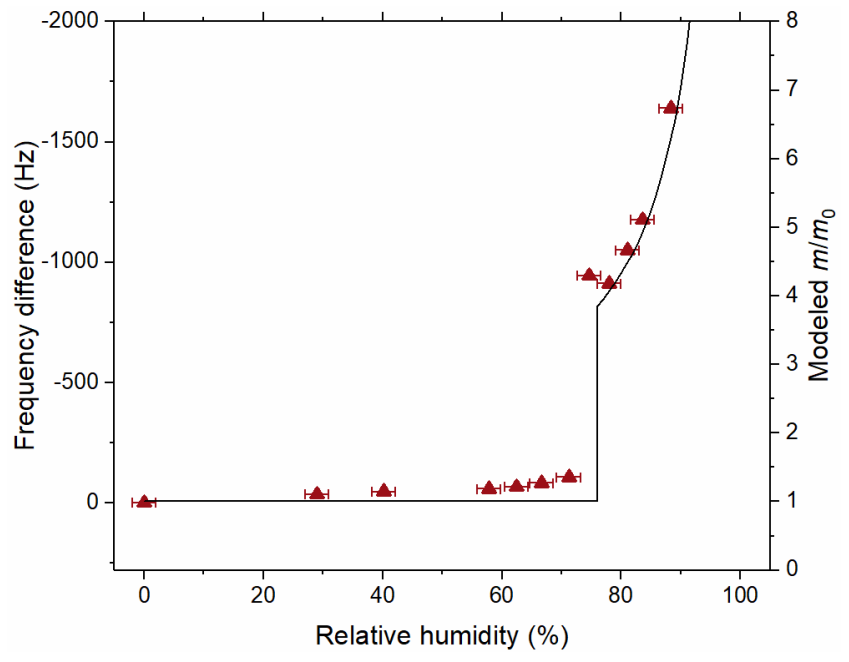

Figure 4. Intermediary comparison of frequency difference $\left(f_{\text {humid }}-f_{\text {dry }}\right)$ to theoretical $\mathrm{m} / \mathrm{m}_{0}$ modelled through E-AIM. Experimental data, taken from humidification mode of second $\mathrm{NaCl}$ run, given by filled triangles (primary $y$-axis) and modelled data given by black line (secondary $y$-axis). Vertical error bars (based on the range of the five measurements) are smaller than the markers (average). Horizontal error bars are based on RH sensor uncertainty $( \pm 2 \%)$. Note that primary axis is reversed due to the inverse linear relationship between frequency shift and mass. 


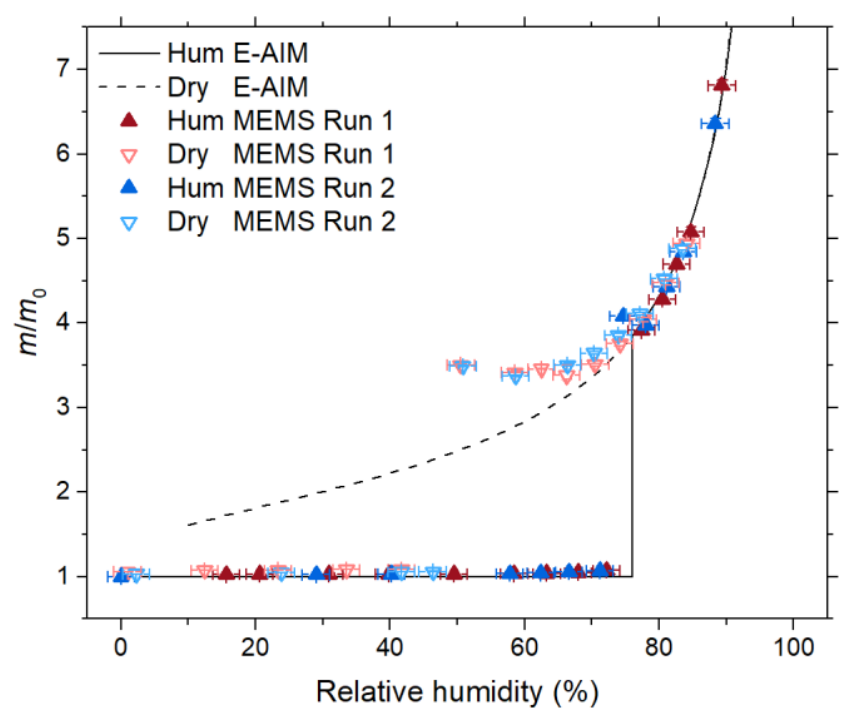

Figure 5. $\mathrm{m} / \mathrm{m}_{0}$ for $\mathrm{NaCl}$ determined using the microresonator for two runs (colored red and blue) for both humidification (dark, filled upwards triangles) and drying modes (light, open downwards triangles) compared to E-AIM model (solid line for humidification and dashed line for drying). Vertical error bars (based on the range of the five measurements) are smaller than the markers (average). Horizontal error bars are based on RH sensor uncertainty $( \pm 2 \%)$.

Phase transitions and hygroscopicity were also assessed for ammonium sulfate (AS) particles. As for $\mathrm{NaCl}$, clear discontinuities in the measured frequency and Q-factor could be observed following deliquescence and efflorescence (Figure S-2). Furthermore, the DRH and ERH determined for AS using MEMS also agree well with previous measurements and the E-AIM model prediction (Table 1). The drying mode frequencies level off below the DRH until efflorescence (from $\sim 75 \%$ RH down to $35-43 \%$ ) in a similar fashion to $\mathrm{NaCl}$, and this is discussed further below.

Inorganic-organic mixture ( $\mathrm{NaCl} / \mathbf{M A})$. Tests were also performed on particles composed of $\mathrm{NaCl}$ and malonic acid (MA) in a 1:1 molar ratio. Particles were prepared and humidified in the same manner as for the pure $\mathrm{NaCl}$ particles above. The raw frequency and Q-factor response to RH is shown in Figure $\mathrm{S}-3$. The final humidogram for $\mathrm{NaCl} / \mathrm{MA}$ is plotted in Figure 6, alongside E-AIM thermodynamic calculations.

Above $~ 55 \% \mathrm{RH}$, the nominal deliquescence point of $\mathrm{MA}$ in this mixture according to E-AIM, the shape of the measured growth curve agrees well with the E-AIM predictions and maps out the transition to a fully deliquesced particle $(55-68 \% \mathrm{RH})$ and subsequent hygroscopic growth $(>68 \% \mathrm{RH})$ well. Disagreement between the measurements and model predictions in terms of the apparent mass loss by the end of the efflorescence-mode measurements are discussed below.

Unlike pure $\mathrm{NaCl}$, previous studies on MA and its mixtures have concluded that the organic component does not effloresce with decreasing $\mathrm{RH}^{9,10,48}$ meaning that even at low $\mathrm{RH}$ a small amount of liquid water is associated with the particles. We simulated this in E-AIM by suppressing the formation of solid MA (grey solid line in Figure 6) alongside a simulation in which both components are initially crystalline (black solid line in Figure 6).

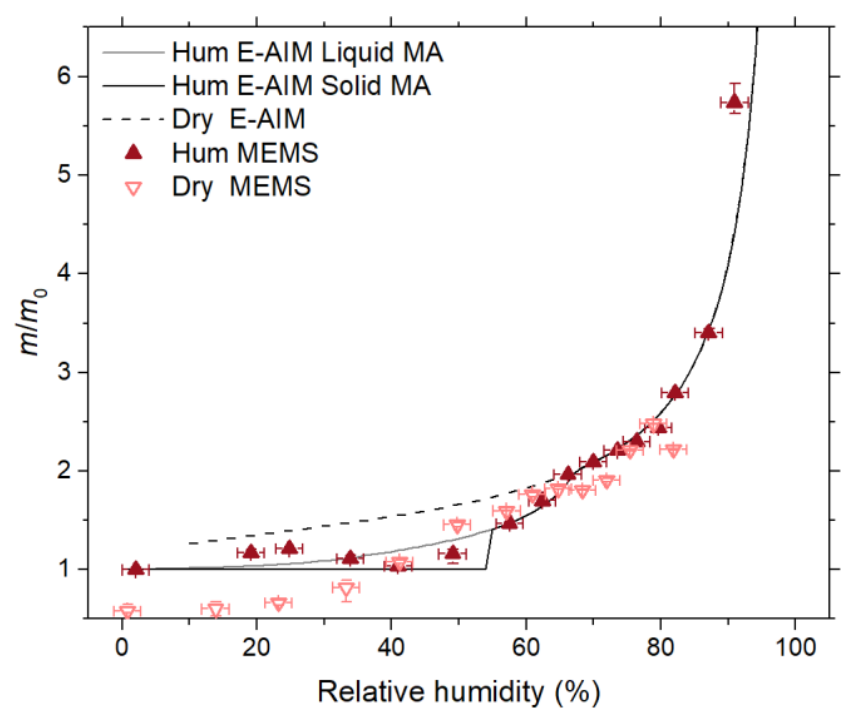

Figure 6. $\mathrm{m} / \mathrm{m}_{0}$ for $\mathrm{NaCl} / \mathrm{MA}$ mixture determined using the microresonator for both humidification (dark, filled upwards triangles) and drying modes (light, open downwards triangles) compared to E-AIM model. E-AIM model covers three scenarios: humidification assuming MA begins as a liquid (solid grey line), or as a solid (solid black line) and drying (dashed black line). Vertical error bars show the range of the five measurements with the quoted value being the average. Horizontal error bars are based on RH uncertainty $( \pm 2 \%)$.

Our data are consistent with a liquid MA phase persisting at all RH. There is no clear evidence for particle phase changes in the frequency and Q-factor measurements (Figure S-3); unlike $\mathrm{NaCl}$, neither quantity shows step changes indicative of a phase transition. Furthermore, the stiffness frequency correction applied to the $\mathrm{NaCl} / \mathrm{MA}$ data was small compared to pure $\mathrm{NaCl}$ (Table S-2). This suggests the damping properties of the particles were similar over the $\mathrm{RH}$ range, consistent with the absence of phase changes. The change in Q-factor during initial resonator loading $(<10 \% \mathrm{RH})$ also suggests a damping (i.e. liquid) material is being collected (discussed in the supporting information and Table S-3).

Discussion of microresonator performance. The microresonator was able to clearly determine the DRH and ERH of the salts (when applicable), but its advantage over other small-scale alternatives (QCM, IDE) to the EDB and HTDMA is its potential to produce accurate humidograms. For the humidification mode, the humidograms followed theoretical models well after the stiffness frequency correction, including for mixed inorganic-organic salts. We now address some of the discrepancies between the MEMS measurements and expected behavior noted above.

The addition of stiffness frequencies $\left(f_{\mathrm{k}}\right)$ to obtain quantitative agreement with theoretical growth curves is consistent with expected changes in damping related to particle phase, particularly discrete phase transitions (as discussed further in the Supplement). However, the $f_{\mathrm{k}}$ obtained here vary with composition and this presents a conceptual problem for future ambient samples of unknown composition. Ambient particles generally contain complex mixtures of components, including a sizable organic fraction. A number of studies suggest that this tends to suppress deliquescence and efflorescence of individual components ${ }^{7,8,56}$, including the mixed $\mathrm{MA} / \mathrm{NaCl}$ particles with low $f_{\mathrm{k}}$ 
here. We therefore anticipate that generally small $f_{\mathrm{k}}$ corrections might be required for ambient samples, which could either be based on an average "ambient $f_{\mathrm{k}}$ " from extensive field testing, or neglected. We outline plans for future work in this important direction in the conclusions.

The $\mathrm{NaCl} / \mathrm{MA}$ growth curve agrees well with the literature and E-AIM predictions, aside from the apparent mass loss by the end of the RH cycle (Figure 6). In frequency terms, this corresponds to a relatively small $200 \mathrm{~Hz}$ difference over the course of the experiment (Figure S-3). Such variation has been seen in similar resonator applications ${ }^{23}$. However, this exceeds the variability over our $\mathrm{NaCl}$ and $\mathrm{AS}$ experiments $(\sim 50 \mathrm{~Hz})$ and in the humidification mode $\mathrm{NaCl} / \mathrm{MA}$ measurement $<50 \% \mathrm{RH}(\sim 110$ $\mathrm{Hz}$ ). We cannot rule out possible partial evaporation of the malonic acid component over the course of the experiment, and future experiments which include surface compositional analysis are merited. However, the generally good agreement between the humidification and drying mode data $>40 \% \mathrm{RH}$, and the lack of observed efflorescence (expected for pure salts and high salt mole fractions ${ }^{8}$ in mixed inorganic/organic systems) suggests that at least a sizeable fraction of the MA remains.

The efflorescent samples, $\mathrm{NaCl}$ and $\mathrm{AS}$, show a "levelling off" in frequency with decreasing RH (Figure 3 and Figure S-2) which corresponds to an overestimated particle mass between the ERH and DRH (Figure 5). Mixed $\mathrm{NaCl} / \mathrm{MA}$ particles (which are assumed to remain liquid at all $\mathrm{RH}$ ) do not show any obvious hysteresis (Figure 6). We propose that contact with the substrate modifies the behavior of efflorescent salts at high (supersaturated) solute concentrations.

Droplet spreading, and crystallization at the droplet-surface interface, may both influence thermodynamic and kinetic properties of electrolyte solutions ${ }^{57-59}$. Eom et al. observed slightly higher apparent $\mathrm{GF}$ in their drying mode data for $\mathrm{NaCl}$ on silicon wafer, consistent with the "levelling off" here ${ }^{57}$. However, this effect was small compared to hydrophilic and/or redox-active surfaces. The resonator also exhibits differential spatial sensitivity, and changes in the spatial distribution and attachment of material on the surface during drying could lead to frequency changes unrelated to mass changes. For instance, drying salt solutions can form "coffee rings" or a range of other solid morphologies $^{58}$. In support of this hypothesis, we note that the Q-factor in this supersaturated region increases with decreasing $\mathrm{RH}$ as the frequency levels off (e.g. 65-45\% RH in Figure 3).

The performance of the system can be improved for hygroscopicity measurements by addressing the two major components, the MIS and the microresonator, individually. The internal volume of the MIS is relatively large (roughly $2.5 \mathrm{~L}$ ) which requires longer times for the internal $\mathrm{RH}$ to equilibrate. This, in turn, lengthens experimental times which can affect results (see discussion on MA evaporation above). As shown by Maldonado-Garcia et al., the volume of a microresonator-based impactor can be drastically reduced ${ }^{32}$ to address this concern albeit at the cost of the flexibility of the MIS. The mass sensitivity of a resonator can be improved by shrinking it (up to the limit where thermomechanical noise dominates $)^{60}$. This is particularly important for ambient samples, which are typically mixtures and less hygroscopic ${ }^{53}$, that require higher sensitivities.

However, microresonators are not solely sensitive to mass (or attachment stiffness) and can also be influenced by, for example, surface charge, temperature, and pressure. In the work here, the temperature response was corrected for using a linear scaling factor based on the internal temperature of the MIS. If larger temperature variations are expected, e.g. during ambient studies, then micro-hotplates ${ }^{61}$ could be integrated to provide controlled temperatures. Factors influencing the mass sensitivity of the microresonator can also be adjusted by selecting a different topology (i.e. the type of resonator) or mode shape (i.e. the mode of vibration).

\section{CONCLUSIONS}

The MIS, a new system for measuring aerosol phase changes and hygroscopicity, was introduced as a low-cost alternative to conventional methods such as an EDB or an HTDMA. The MIS collects the aerosol onto microfabricated resonators whose resonant frequency responds to the collected aerosol mass.

The MIS offers some key advantages over conventional methods: (1) it is able to measure a mixture of particles (unlike an EDB) which is particularly useful for ambient sampling; (2) it measures the same aerosol throughout a given experiment (unlike an HTDMA) to remove the influence of any compositional fluctuations of the measured aerosol; and (3) in principle, both sub- and super-micron particle sizes can be analyzed, unlike an EDB $(>5 \mu \mathrm{m})$ or an HTDMA $(<1 \mu \mathrm{m})$. Additionally, the MIS design enables routine determination of hygroscopicity after particle collection with simple changes to the setup.

For pure inorganic salts ( $\mathrm{NaCl}$ and $\mathrm{AS})$ the detected DRHs and ERHs were in agreement with previous experimental studies and theoretical thermodynamic models. The transitions between phases were clearly distinguishable in both the measured resonant frequency (a measure of mass) and the quality factor (a measure of damping).

The MIS was also able to produce hygroscopic growth curves, unlike other resonant systems for detecting phase changes ${ }^{23}$, for both pure inorganic particles and inorganic-organic mixtures ( $\mathrm{NaCl} / \mathrm{MA})$. The growth curves match the shape of expected theoretical curves but require scaling (with a stiffness frequency) to accurately convert from frequency measurements to mass measurements. Discrepancies in the curves persist, particularly during efflorescence, presumably due to aerosol-resonator surface interactions.

These discrepancies were less apparent in mixed samples (due to the lack of full efflorescence). While this suggests ambient samples may be relatively unaffected by surface effects, tests on real-world particles are an important next step for the project. Since theoretical growth curves are unavailable for such samples, we propose to compare the measured humidograms to those obtained from a co-located reference instrument. This will allow us to assess whether ambient stiffness corrections are required, and if so, whether a general "ambient $f_{\mathrm{k}}$ " could be derived from a large number of samples. Since more complex particles may be subject to continuous phase transitions (e.g. related to viscosity), we also propose additional laboratory tests on particles whose $\mathrm{RH}$-viscosity relationship is well known, such as sucrose ${ }^{62}$.

To extract additional information in ambient studies using the presented methodology, future impactors could be multiple stage cascade impactors. These impactor designs separate particles into discrete size bins (based on diameter) to produce full particle distributions. Since ambient particle composition is size-dependent, implementing cascade impactors would allow for size-resolved particle hygroscopicity to be assessed, similar to an HTDMA. 


\section{ASSOCIATED CONTENT}

\section{Supporting Information}

The Supporting Information is available free of charge on the ACS Publications website.

Additional experimental figures, derivation of stiffness frequency and calculated values, and the measured changes in quality factor before and after deliquescence (PDF).

\section{AUTHOR INFORMATION}

\section{Corresponding Authors}

*E-mail: arthur.zielinski@atm.ch.cam.ac.uk

*E-mail: pjg48@cam.ac.uk

\section{Author Contributions}

$\uparrow \mathrm{ATZ}$ and PJG contributed equally to this work.

ATZ, PJG and PTG conceived and designed the study. PJG and ATZ performed the experiments and modelling, analyzed the data and wrote the manuscript. All authors assisted with manuscript preparation.

\section{Notes}

The authors declare no competing financial interest.

\section{ACKNOWLEDGMENT}

This work was funded by the European Research Council (grant 279405) and the European Union's Horizon 2020 research and innovation programme through the EUROCHAMP-2020 Infrastructure Activity under grant agreement No 730997. ATZ thanks the Natural Sciences and Engineering Research Council of Canada, the Sir Winston Churchill Society of Edmonton, and the Cambridge Trust for funding of the $\mathrm{PhD}$ degree.

\section{REFERENCES}

(1) Boucher, O.; Randall, D.; Artaxo, P.; Bretherton, C.; Feingold, G.; Forster, P.; Kerminen, V.-M.; Kondo, Y.; Liao, H.; Lohmann, U.; et al. Clouds and Aerosols. In Climate Change 2013: The Physical Science Basis. Contribution of Working Group I to the Fifth Assessment Report of the Intergovernmental Panel on Climate Change; Stocker, T. F., Qin, D., Plattner, G.-K., Tignor, M., Allen, S. K., Boschung, J., Nauels, A., Xia, Y., Bex, V., Midgley, P. M., Eds.; 2013.

(2) Pope, C. A.; Ezzati, M.; Dockery, D. W. Fine-Particulate Air Pollution and Life Expectancy in the United States. N. Engl. J. Med. 2009, 360, 376-386.

(3) Singh, A.; Bloss, W. J.; Pope, F. D. 60 Years of UK Visibility Measurements: Impact of Meteorology and Atmospheric Pollutants on Visibility. Atmos. Chem. Phys. 2017, 17, 20852101.

(4) Abbatt, J. P. D.; Lee, A. K. Y.; Thornton, J. A. Quantifying Trace Gas Uptake to Tropospheric Aerosol: Recent Advances and Remaining Challenges. Chem. Soc. Rev. 2012, 41, 6555-6581.

(5) Ye, Q.; Shipley, E.; Ding, X.; Ye, P.; Sullivan, R. C.; Donahue, N. M. Mixing of Secondary Organic Aerosols versus Relative Humidity. 2016, No. 16.

(6) Oberdörster, G.; Oberdörster, E.; Oberdörster, J. Nanotoxicology: An Emerging Discipline Evolving from Studies of Ultrafine Particles. Environ. Health Perspect. 2005, 113, 823-839.

(7) Bertram, A. K.; Martin, S. T.; Hanna, S. J.; Smith, M. L.; Bodsworth, A.; Chen, Q.; Kuwata, M.; Liu, A.; You, Y.; Zorn, S. R. Predicting the Relative Humidities of Liquid-Liquid Phase Separation, Efflorescence, and Deliquescence of Mixed Particles of Ammonium Sulfate, Organic Material, and Water Using the Organic-to-Sulfate Mass Ratio of the Particle and the Oxygen-toCarbon El. Atmos. Chem. Phys. 2011, 11, 10995-11006. C. F., Abbatt, J. P. D. A Study of the Phase Transition Behavior of Internally Mixed Ammonium Sulfate - Malonic Acid
Aerosols. Atmos. Chem. Phys. 2004, No. 2002, 1451-1459.

Peng, C.; Chan, M. N.; Chan, C. K. The Hygroscopic Properties of Dicarboxylic and Multifunctional Acids: Measurements and UNIFAC Predictions. Environ. Sci. Technol. 2001, 35, 44954501.

Pope, F. D.; Dennis-Smither, B. J.; Griffiths, P. T.; Clegg, S. L.; Cox, R. A. Studies of Single Aerosol Particles Containing Malonic Acid, Glutaric Acid, and Their Mixtures with Sodium Chloride. I. Hygroscopic Growth. J. Phys. Chem. A 2010, 114, 5335-5341.

Cohen, M. D.; Flagan, R. C.; Seinfeld, J. H. Studies of Concentrated Electrolyte Solutions Using the Electrodynamic Balance. 1. Water Activities for Single-Electrolyte Solutions. $J$. Phys. Chem. 1987, 91, 4563-4571.

Griffiths, P. T.; Borlace, J.-S.; Gallimore, P. J.; Kalberer, M.; Herzog, M.; Pope, F. D. Hygroscopic Growth and Cloud Activation of Pollen: A Laboratory and Modelling Study. Atmos. Sci. Lett. 2012, 13, 289-295.

Pope, F. D.; Gallimore, P. J.; Fuller, S. J.; Cox, R. A.; Kalberer, M. Ozonolysis of Maleic Acid Aerosols: Effect upon Aerosol Hygroscopicity, Phase and Mass. Environ. Sci. Technol. 2010, 44, 6656-6660.

Marsh, A.; Rovelli, G.; Song, Y.; Pereira, K. L.; Willoughby, R. E.; Bzdek, B. R.; Hamilton, J. F.; Orr-ewing, A. J.; Topping, O.; Reid, J. P. Accurate Representations of the Physicochemical Properties of Atmospheric Aerosols: When Are Laboratory Measurements of Value ? Faraday Discuss. 2017, 1-23.

Tong, H. J.; Reid, J. P.; Bones, D. L.; Luo, B. P.; Krieger, U. K. Measurements of the Timescales for the Mass Transfer of Water in Glassy Aerosol at Low Relative Humidity and Ambient Temperature. Atmos. Chem. Phys. 2011, 11, 4739-4754.

Tong, H.-J.; Fitzgerald, C.; Gallimore, P. J.; Kalberer, M.; Kuimova, M. K.; Seville, P. C.; Ward, A. D.; Pope, F. D. Rapid Interrogation of the Physical and Chemical Characteristics of Salbutamol Sulphate Aerosol from a Pressurised Metered-Dose Inhaler (pMDI). Chem. Commun. 2014, 50, 15499-15502.

Duplissy, J.; DeCarlo, P. F.; Dommen, J.; Alfarra, M. R.; Metzger, a.; Barmpadimos, I.; Prevot, a. S. H.; Weingartner, E.; Tritscher, T.; Gysel, M.; et al. Relating Hygroscopicity and Composition of Organic Aerosol Particulate Matter. Atmos. Chem. Phys. 2011, 11, 1155-1165.

Wu, Z. J.; Zheng, J.; Shang, D. J.; Du, Z. F.; Wu, Y. S.; Zeng, L. M.; Wiedensohler, A.; Hu, M. Particle Hygroscopicity and Its Link to Chemical Composition in the Urban Atmosphere of Beijing , China, during Summertime. Atmos. Chem. Phys 2016, 16, 1123-1138.

Liu, B. Y. H.; Pui, D. Y. H.; Whitby, K. T.; Kittelson, D. B.; Kousaka, Y.; McKenzie, R. L. THE AEROSOL DETECTOR MOBILITY CHROMATOGRAPH : A NEW FOR SULFURIC ACID AEROSOLS. Atmos. Environ. 1977, 12, 99-104.

Swietlicki, E.; Hansson, H.-C.; Hameri, K.; Svenningsson, B.; Massling, A.; Mcfiggans, G. B.; McMurry, P. H.; Petäjä, T.; Tunved, P.; Gysel, M.; et al. Hygroscopic Properties of Submicrometer Atmospheric Aerosol Particles Measured with $\mathrm{H}$ TDMA Instruments in Various Environments - a Review. Tellus $B$ 2008, 60B, 432-469.

Duplissy, J.; Gysel, M.; Sjogren, S.; Meyer, N.; Good, N.; Kammermann, L.; Michaud, V.; Weigel, R.; Martins dos Santos, S.; Gruening, C.; et al. Intercomparison Study of Six HTDMAs : Results and Recommendations. Atmos. Meas. Tech. 2009, 2, 363378.

Schindelholz, E.; Tsui, L. K.; Kelly, R. G. Hygroscopic Particle Behavior Studied by Interdigitated Array Microelectrode Impedance Sensors. J. Phys. Chem. A 2014, 118, 167-177.

Arenas, K. J. L.; Schill, S. R.; Malla, A.; Hudson, P. K. Deliquescence Phase Transition Measurements by Quartz Crystal Microbalance Frequency Shifts. J. Phys. Chem. A 2012, 116, 7658-7667.

Dybwad, G. L. A Sensitive New Method for the Determination of Adhesive Bonding between a Particle and a Substrate. J. Appl. Phys. 1985, 58, 2789-2790.

Vittorias, E.; Kappl, M.; Butt, H. J.; Johannsmann, D. Studying Mechanical Microcontacts of Fine Particles with the Quartz Crystal Microbalance. Powder Technol. 2010, 203, 489-502.

(26) Pomorska, A.; Shchukin, D.; Hammond, R.; Cooper, M. A.; 
Grundmeier, G.; Johannsmann, D. Positive Frequency Shifts Observed upon Adsorbing Micron-Sized Solid Objects to a Quartz Crystal Microbalance from the Liquid Phase. Anal. Chem. 2010, 82, 2237-2242.

(27) Pang, W.; Zhao, H.; Kim, E. S.; Zhang, H.; Yu, H.; Hu, X Piezoelectric Microelectromechanical Resonant Sensors for Chemical and Biological Detection. Lab Chip 2012, 12, 29.

(28) Tamayo, J.; Kosaka, P. M.; Ruz, J. J.; San Paulo, Á.; Calleja, M. Biosensors Based on Nanomechanical Systems. Chem. Soc. Rev. 2013, 42, 1287-1311.

(29) Verd, J.; Sansa, M.; Uranga, A.; Perez-Murano, F.; Segura, J.; Barniol, N. Metal Microelectromechanical Oscillator Exhibiting Ultra-High Water Vapor Resolution. Lab Chip 2011, 11, 2670 2672.

(30) Southworth, D. R.; Bellan, L. M.; Linzon, Y.; Craighead, H. G.; Parpia, J. M. Stress-Based Vapor Sensing Using Resonant Microbridges. Appl. Phys. Lett. 2010, 96, 1-3.

(31) Penza, M.; Cassano, G. Relative Humidity Sensing by PVACoated Dual Resonator SAW Oscillator. Sensors Actuators B Chem. 2000, 68, 300-306.

(32) Maldonado-Garcia, M.; Kumar, V.; Wilson, J. C.; Pourkamali, S. Chip-Scale Implementation and Cascade Assembly of Particulate Matter Collectors with Embedded Resonant Mass Balances. IEEE Sens. J. 2016, 17, 1617-1625.

(33) Wasisto, H. S.; Uhde, E.; Peiner, E. Enhanced Performance of Pocket-Sized Nanoparticle Exposure Monitor for Healthy Indoor Environment. Build. Environ. 2016, 95, 13-20.

(34) Thomas, S.; Cole, M.; Villa-López, F. H.; Gardner, J. W. High Frequency Surface Acoustic Wave Resonator-Based Sensor for Particulate Matter Detection. Sensors Actuators A Phys. 2016, 244, 138-145.

(35) Zielinski, A. T.; Kalberer, M.; Jones, R. L.; Prasad, A.; Seshia, A. A. Particulate Mass Sensing with Piezoelectric Bulk Acoustic Mode Resonators. In Internationl Frequency Control Symposium (IFCS); IEEE: New Orleans, USA, 2016.

(36) Prasad, A.; Charmet, J.; Seshia, A. A. Simultaneous Interrogation of High-Q Modes in a Piezoelectric-on-Silicon Micromechanical Resonator. Sensors Actuators A Phys. 2016, 238, 207-214.

(37) Zielinski, A. T.; Prasad, A.; Seshia, A. A.; Kalberer, M.; Jones, R. L. Effects of Spatial Sensitivity on Mass Sensing with Bulk Acoustic Mode Resonators. Sensors Actuators A Phys. 2015, 236, 369-379.

(38) Campanella, H.; Martincic, E.; Nouet, P.; Uranga, A.; Esteve, J. Analytical and Finite-Element Modeling of Localized-Mass Sensitivity of Thin-Film Bulk Acoustic-Wave Resonators (FBAR). IEEE Sens. J. 2009, 9, 892-901.

(39) Prasad, A.; Seshia, A. A.; Zielinski, A. T.; Kalberer, M.; Jones, R. L. Studying Particulate Adsorption by Drying Droplets on a Microfabricated Electro-Acoustic Resonator. In European Frequency and Time Forum (EFTF); IEEE: Neuchâtel, Switzerland, 2014; pp 28-31.

(40) Paprotny, I.; Doering, F.; Solomon, P. A.; White, R. M.; Gundel, L. A. Microfabricated Air-Microfluidic Sensor for Personal Monitoring of Airborne Particulate Matter: Design, Fabrication, and Experimental Results. Sensors Actuators A Phys. 2013, 201, 506-516.

(41) Zielinski, A. T.; Weckman, N. E.; Jones, R. L.; Kalberer, M.; Seshia, A. A. Extending the Lifetime of Resonant Atmospheric Particulate Mass Sensors with Solvent Rinses. IEEE Sensors Lett. 2017, 1, 1-4.

(42) Soysal, U.; Géhin, E.; Algré, E.; Berthelot, B.; Da, G.; Robine, E. Aerosol Mass Concentration Measurements: Recent Advancements of Real-Time Nano / Micro Systems. J. Aeroso 2017, 114, 42-54.

(43) Bertke, M.; Wu, W.; Wasisto, H. S.; Uhde, E.; Peiner, E. SizeSelective Electrostatic Sampling and Removal of Nanoparticesl on Silicon Cantilever Sensors for Air-Quality Monitoring. In Transducers; IEEE: Kaohsiung, Taiwan, 2017; Vol. 1, pp 14931496.
Saukko, E.; Lambe, A. T.; Massoli, P.; Koop, T.; Wright, J. P.; Croasdale, D. R.; Pedernera, D. A.; Onasch, T. B.; Laaksonen, A.; Davidovits, P.; et al. Humidity-Dependent Phase State of SOA Particles from Biogenic and Anthropogenic Precursors. Atmos. Chem. Phys. 2012, 12, 7517-7529.

(45) Kaajakari, V.; Mattila, T.; Oja, A.; Seppa, H. Nonlinear Limits for Single-Crystal Silicon Microresonators. $J$ Microelectromechanical Syst. 2004, 13, 715-724.

(46) Petersan, P. J.; Anlage, S. M. Measurement of Resonant Frequency and Quality Factor of Microwave Resonators: Comparison of Methods. J. Appl. Phys. 1998, 84, 3392-3402.

(47) Lee, J. E.-Y.; Seshia, A. A. Direct Parameter Extraction in Feedthrough-Embedded Capacitive MEMS Resonators. Sensors Actuators A Phys. 2011, 167, 237-244.

(48) Clegg, S. L.; Seinfeld, J. H. Thermodynamic Models of Aqueous Solutions Containing Inorganic Electrolytes and Dicarboxylic Acids at 298.15 K. 1. The Acids as Nondissociating Components. J. Phys. Chem. A 2006, 110, 5692-5717.

(49) Clegg, S. L.; Brimblecombe, P.; Wexler, A. S. Thermodynamic Model of the System H+ - NH4+ - SO42- - NO3- - H2O at Tropospheric Temperatures. J Phys Chem A 1998, 102, $2137-$ 2154.

(50) Sauerbrey, G. Verwendung von Schwingquarzen Zur Wägung Dünner Schichten Und Zur Mikrowägung. Zeitschrift für Phys. 1959, 155, 206-222.

(51) Lee, J. E.-Y.; Bahreyni, B.; Zhu, Y.; Seshia, A. A. Ultrasensitive Mass Balance Based on a Bulk Acoustic Mode Single-Crystal Silicon Resonator. Appl. Phys. Lett. 2007, 91, 89-92.

(52) Tang, I. N.; Munkelwitz, H. R. Water Activities, Densities, and Refractive Indices of Aqueous Sulfates and Sodium Nitrate Droplets of Atmospheric Importance. J. Geophys. Res. 1994, 99, 18801-18808.

(53) Cruz, C. N.; Pandis, S. N. Deliquescence and Hygroscopic Growth of Mixed Inorganic - Organic Atmospheric Aerosol. Environ. Sci. Technol. 2000, 34, 4313-4319.

(54) Schuttlefield, J.; Al-Hosney, H.; Zachariah, A.; Grassian, V. H. Attenuated Total Reflection Fourier Transform Infrared Spectroscopy to Investigate Water Uptake and Phase Transitions in Atmospherically Relevant Particles. Appl. Spectrosc. 2007, 61, 283-292.

(55) Weis, D. D.; Ewing, G. E. Water Content and Morphology of Sodium Chloride Aerosol Particles. J. Geophys. Res. Atmos. 1999, 104, 21275-21285.

(56) Robinson, C. B.; Schill, G. P.; Tolbert, M. A. Optical Growth of Highly Viscous Organic/sulfate Particles. J Atmos Chem 2014 71, 145-156.

(57) Eom, H.; Gupta, D.; Li, X.; Jung, H.; Kim, H.; Ro, C. Influence of Collecting Substrates on the Characterization of Hygroscopic Properties of Inorganic Aerosol Particles. Anal. Chem. 2014, 86, 2648-2656.

(58) Shahidzadeh-Bonn, N.; Rafai, S.; Bonn, D.; Wegdam, G.; V, U. R. N.; Uni, V. Salt Crystallization during Evaporation : Impact of Interfacial Properties. Langmuir 2008, 24, 8599-8605.

(59) Hosny, N. A.; Fitzgerald, C.; Vyšniauskas, A.; Athanasiadis, A.; Berkemeier, T.; Uygur, N.; Pöschl, U.; Shiraiwa, M.; Kalberer, M.; Pope, F. D.; et al. Direct Imaging of Changes in Aerosol Particle Viscosity upon Hydration and Chemical Aging. Chem. Sci. 2016, 7, 1357-1367.

(60) Ekinci, K. L.; Yang, Y. T.; Roukes, M. L. Ultimate Limits to Inertial Mass Sensing Based upon Nanoelectromechanical Systems. J. Appl. Phys. 2004, 95, 2682-2689.

(61) Udrea, F.; Gardner, J. W.; Setiadi, D.; Covington, J. A.; Dogaru, T.; Lu, C. C.; Milne, W. I. Design and Simulations of SOI CMOS Micro-Hotplate Gas Sensors. Sensors Actuators B Chem. 2001, 78, 180-190.

(62) Hosny, N. A.; Fitzgerald, C.; Tong, C.; Kalberer, M.; Kuimova M. K.; Pope, F. D. Fluorescent Lifetime Imaging of Atmospheric Aerosols: A Direct Probe of Aerosol Viscosity. Faraday Discuss. 2013, 165, 343-356. 
Table of Contents (TOC) graphic:

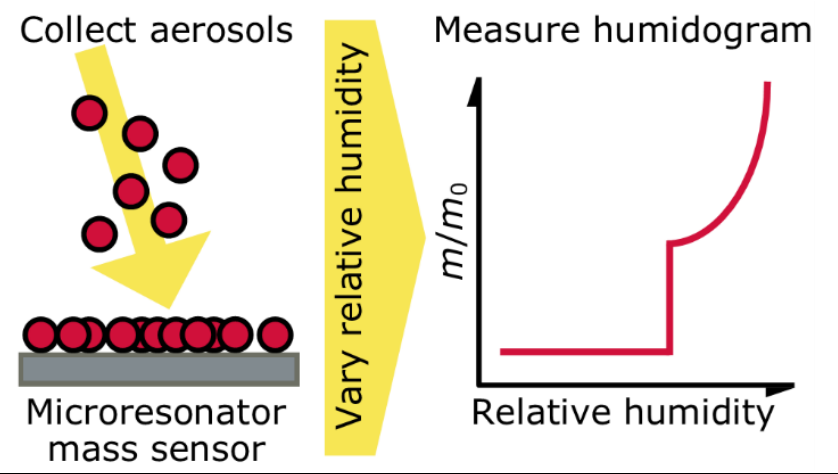

